\title{
Home hemodialysis treatment and outcomes: retrospective analysis of the Knowledge to Improve Home Dialysis Network in Europe (KIHDNEy) cohort
}

Shashidhar Cherukuri ${ }^{1}$, Maria Bajo ${ }^{2}$, Giacomo Colussi ${ }^{3}$, Roberto Corciulo ${ }^{4}$, Hafedh Fessi ${ }^{5}$, Maxence Ficheux ${ }^{6}$, Maria Slon ${ }^{7}$, Eric Weinhandl ${ }^{8,9^{*}}$ (D) and Natalie Borman ${ }^{10}$

\begin{abstract}
Background: Utilization of home hemodialysis (HHD) is low in Europe. The Knowledge to Improve Home Dialysis Network in Europe (KIHDNEy) is a multi-center study of HHD patients who have used a transportable hemodialysis machine that employs a low volume of lactate-buffered, ultrapure dialysate per session. In this retrospective cohort analysis, we describe patient factors, HHD prescription factors, and biochemistry and medication use during the first 6 months of HHD and rates of clinical outcomes thereafter.

Methods: Using a standardized digital form, we recorded data from 7 centers in 4 Western European countries. We retained patients who completed $\geq 6$ months of HHD. We summarized patient and HHD prescription factors with descriptive statistics and used mixed modeling to assess trends in biochemistry and medication use. We also estimated long-term rates of kidney transplant and death.

Results: We identified 129 HHD patients; 104 (81\%) were followed for $\geq 6$ months. Mean age was 49 years and 66\% were male. Over $70 \%$ of patients were prescribed 6 sessions per week, and the mean treatment duration was $15.0 \mathrm{~h}$ per week. Median HHD training duration was 2.5 weeks. Mean standard $K t N_{\text {urea }}$ was nearly 2.7 at months 3 and 6. Pre-dialysis biochemistry was generally stable. Between baseline and month 6 , mean serum bicarbonate increased from 23.1 to $24.1 \mathrm{mmol} / \mathrm{L}(P=0.01)$, mean serum albumin increased from 36.8 to $37.8 \mathrm{~g} / \mathrm{L}(P=0.03)$, mean serum C-reactive protein increased from 7.3 to $12.4 \mathrm{mg} / \mathrm{L}(P=0.05)$, and mean serum potassium decreased from 4.80 to 4 . $59 \mathrm{mmol} / \mathrm{L}(P=0.01)$. Regarding medication use, the mean number of antihypertensive medications fell from 1.46 agents per day at HHD initiation to 1.01 agents per day at 6 months $(P<0.001)$, but phosphate binder use and erythropoiesis-stimulating agent dose were stable. Long-term rates of kidney transplant and death were 15.3 and 5.4 events per 100 patient-years, respectively.
\end{abstract}

Conclusions: Intensive HHD with low-flow dialysate delivers adequate urea clearance and good biochemical outcomes in Western European patients. Intensive HHD coincided with a large decrease in antihypertensive medication use. With relatively rapid training, HHD should be considered in more patients.

Keywords: Adequacy, Antihypertensive medication, Home hemodialysis, Intensive hemodialysis, Kidney transplant, Lactate, Low-flow dialysate, Ultrapure dialysate

\footnotetext{
* Correspondence: eweinhandl@nxstage.com; wein0205@umn.edu

${ }^{8}$ NxStage Medical, Inc., 350 Merrimack Street, Lawrence, MA 01843, USA

${ }^{9}$ Department of Pharmaceutical Care and Health Systems, University of

Minnesota, Minneapolis, MN, USA

Full list of author information is available at the end of the article
}

(c) The Author(s). 2018 Open Access This article is distributed under the terms of the Creative Commons Attribution 4.0 International License (http://creativecommons.org/licenses/by/4.0/), which permits unrestricted use, distribution, and reproduction in any medium, provided you give appropriate credit to the original author(s) and the source, provide a link to the Creative Commons license, and indicate if changes were made. The Creative Commons Public Domain Dedication waiver (http://creativecommons.org/publicdomain/zero/1.0/) applies to the data made available in this article, unless otherwise stated. 


\section{Background}

The prevalence of chronic kidney disease (CKD) is growing internationally, partly due to the steadily growing prevalence of diabetes. This has led to a rise in need for renal replacement therapy (RRT); the number of patients receiving RRT is expected to double by 2030 [1]. Between 2013 and 2014 alone, the number of adult patients receiving RRT in the United Kingdom rose $4.0 \%$ [2]. Although use of hemodialysis outpaces use of peritoneal dialysis in the UK and almost every other country [3], patients on home hemodialysis (HHD) represent only slightly more than $4 \%$ of dialysis patients in the UK [2]. Across all of Europe, patients on HHD represent $<2 \%$ of dialysis patients [4]. Compared to in-center hemodialysis, HHD is associated with lower risk of cardiovascular death and hospitalization $[5,6]$. This association may reflect increased treatment frequency, which has been shown in randomized clinical trials to reduce left ventricular mass, improve blood pressure control, and lower serum phosphorus [7-12]. HHD also permits patients the flexibility to dialyze at times that they choose. On the other hand, HHD is associated with higher risk of infection-related hospitalization, compared to in-center hemodialysis [6]. Increased treatment frequency may increase risk of vascular access complications [13].

Despite the potential benefits of HHD, utilization of the modality is low. Historically, this has been attributed to cost and logistics. In the UK, funding for HHD setup costs are a challenge for most hospitals, as the therapy is not included in the tariff set by the specialist commissioners. The recommendation from the National Institute of Clinical Excellence (NICE) to provide HHD to all suitable patients has encouraged renal units to improve HHD programs [14]. Introduction of more compact and user-friendly dialysis machines has also changed the way that patients are dialyzed at home. The aim of this study is to describe patient and treatment factors, short-term biochemical outcomes, and long-term clinical outcomes in HHD patients at European centers that participate in the Knowledge to Improve Home Dialysis Network in Europe (KIHDNEy). The overarching aim of KIHDNEy is to evaluate an array of outcomes on intensive HHD with low-volume dialysate, a newer modality in Europe than in North America.

\section{Methods}

\section{Study cohort}

We performed a retrospective cohort study of anonymized data that were voluntarily provided by 7 dialysis centers throughout Europe. Centers were in England (Portsmouth), France (Caen, Paris), Italy (Bari, Niguarda [Milan]), and Spain (Madrid, Navarre). All patients in the KIHDNEy cohort initiated HHD with the NxStage
System One (NxStage Medical, Lawrence, Massachusetts, United States), a portable hemodialysis machine that employs a low volume of lactate-buffered, ultrapure dialysate per session and inverts the traditional ratio between dialysate and blood flow rates. Patients used either a set of 5-1 bags of sterile, premixed dialysate ("Express System") or fluid that was produced in the home with 5-1 bags of dialysate concentrate and purified tap water ("PureFlow SL"), without need for a reverse osmosis system. Preceding initiation of HHD, patients were educated in a health care facility about the practice of HHD (including cannulation) and technical aspects of the machine.

\section{Patient factors}

During 2015, centers entered data into a standardized Microsoft Excel worksheet. Data comprised patient characteristics; HHD prescription factors; standard $K t / V_{\text {urea }}$ and ultrafiltration volume after 3 and 6 months of HHD; pre-dialysis biochemical parameters at baseline and after 3 and 6 months of HHD; and medication use at baseline and after 3 and 6 months of HHD. Medications comprised erythropoiesis-stimulating agents, heparin, antihypertensive agents, and phosphate binders; units of darbepoetin alfa were converted to units of epoetin alfa-equivalent by multiplying by 250 . We also derived ultrafiltration rate after 3 and 6 months of HHD, but with hemodialysis session duration and weight ascertained at baseline. In addition, centers entered data regarding long-term outcomes, including kidney transplant, return to in-center hemodialysis, and death. Patients were followed until October 31, 2015.

\section{Statistical analysis}

Centers were instructed to enter data only for patients who completed $\geq 6$ months of HHD. Therefore, we retained patients who initiated HHD no later than April 30, 2015, and excluded any retained patient with $<6$ months of follow-up. Furthermore, we excluded patients with missing data regarding HHD prescription factors. We used descriptive analysis to assess patient characteristics and HHD prescription factors. For each clearance and biochemical parameter, we calculated the mean, standard deviation, median, interquartile range, and 10th-90th percentile interval at baseline (as applicable) and months 3 and 6. For each parameter, we assessed statistical significance of the linear trend across measured times; the test was derived from a linear mixed model of the parameter regressed on time, with random effects (intercept and slope) for each patient, but without further covariate adjustment. With long-term follow-up, we estimated the cumulative incidence of kidney transplant, return to in-center hemodialysis, and death, beginning at 6 months 
after HHD initiation and ending at the earlier of 48 months after HHD initiation or October 31, 2015. All statistical analyses were performed with SAS, version 9.4 (Cary, North Carolina, United States) and R, version 3.2.3 (Vienna, Austria).

\section{Results}

We collected data regarding 129 patients in 7 centers. After we excluded patients with missing data regarding the home hemodialysis prescription $(n=2)$, patients who initiated HHD after April 30, $2015(n=14)$, and patients with $<6$ months of HHD before therapy attrition $(n=9)$, we retained 104 (81\%) patients for analysis (Fig. 1). Therapy attrition was attributable to kidney transplant and return to in-center HD; the latter was due to both medical complications and psychosocial issues. Among retained patients, we identified 59 (57\%) patients in England, 23 (22\%) in France, 10 (10\%) in Italy, and 12 (12\%) in Spain.

Patient characteristics are displayed in Table 1. Mean age was 49 years (range, 19 to 75 years) and 66\% of patients were male. Merely $15 \%$ of patients had either diabetes mellitus or hypertensive nephrosclerosis as their primary renal diagnosis. Prevalence of moderate (body mass index, $\left.30-34 \mathrm{~kg} / \mathrm{m}^{2}\right)$, severe $\left(35-39 \mathrm{~kg} / \mathrm{m}^{2}\right)$, and morbid $\left(\geq 40 \mathrm{~kg} / \mathrm{m}^{2}\right)$ obesity was $13 \%, 6 \%$, and $3 \%$, respectively. The Charlson comorbidity score was $\leq 6$ points in nearly all patients. Most patients were on conventional hemodialysis before HHD initiation; only $16 \%$ of patients were incident cases of end stage renal disease (ESRD).

HHD prescription factors are displayed in Table 2. Over $70 \%$ of patients were prescribed 6 sessions per week. Mean (standard deviation) hemodialysis hours per session and per week were $2.6(0.4)$ and 15.0 (2.9), respectively, and more than $68 \%$ received $\geq 15 \mathrm{~h}$ per week. Dialysate preparation varied by country: in France and Italy, only premixed dialysate was used; in Spain, only dialysate concentrate was used; and in the United Kingdom, both preparations were used, although dialysate concentrate was dominant (86\%). Most patients dialyzed with a fistula. Regarding the number of training weeks, mean and median (interquartile range) estimates were 3.8 and 2.5 (3.0), respectively; regarding the number of training sessions, corresponding estimates were 16.8 and 10.0 (16.5) respectively (Fig. 2). Training duration was $\leq 2$ weeks in $50 \%$ of all patients and $80 \%$ of patients in the United Kingdom.

Details of hemodialytic clearance are displayed in Table 3 . With HHD, mean standard $K t / V_{\text {urea }}$ was nearly 2.7 at months 3 and 6 and roughly $90 \%$ of patients had standard $K t / V_{\text {urea }} \geq 2.1$. Among the minority of patients with recorded ultrafiltration volume at months 3 and 6 , mean ultrafiltration volume was roughly $1 \mathrm{~L}$, mean

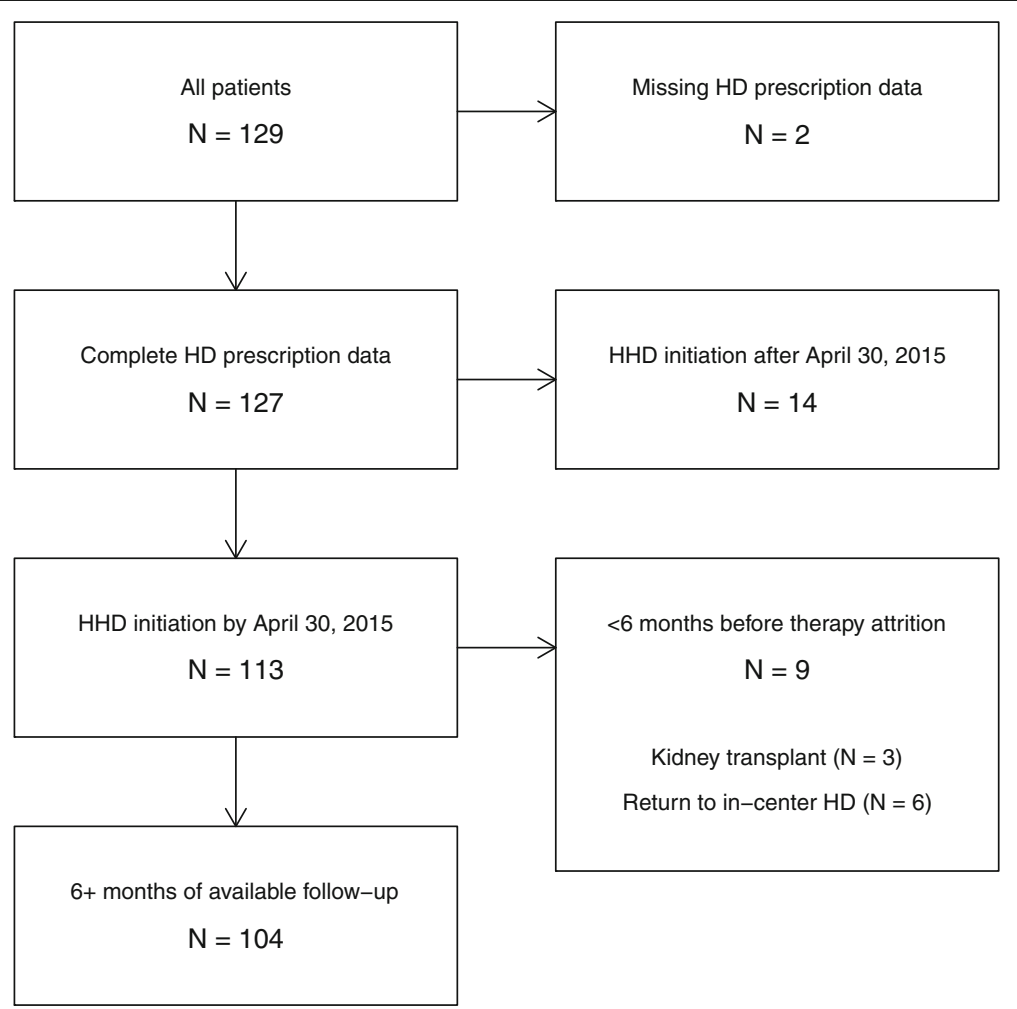

Fig. 1 Sample size of study cohort, with iterative application of inclusion criteria. Abbreviations: HD, hemodialysis; HHD, home hemodialysis 
Table 1 Home hemodialysis patient characteristics

\begin{tabular}{|c|c|}
\hline & Statistic \\
\hline \multicolumn{2}{|l|}{ Age (years) } \\
\hline Mean (SD) & $49.3(12.8)$ \\
\hline Median (IQR) & $49(19)$ \\
\hline 10th-90th percentile interval & $31.6-65.0$ \\
\hline \multicolumn{2}{|l|}{ Sex (\%) } \\
\hline Female & 33.7 \\
\hline Male & 66.3 \\
\hline \multicolumn{2}{|l|}{ Primary renal diagnosis (\%) } \\
\hline Diabetes mellitus & 9.6 \\
\hline Hypertensive nephrosclerosis & 5.8 \\
\hline Glomerulonephritis & 29.8 \\
\hline Polycystic kidney disease & 10.6 \\
\hline Other diagnosis & 44.2 \\
\hline \multicolumn{2}{|l|}{ Body mass index $\left(\mathrm{kg} / \mathrm{m}^{2}\right)$} \\
\hline Mean (SD) & $26.7(6.0)$ \\
\hline Median (IQR) & $25.7(7.5)$ \\
\hline 10th-90th percentile interval & $20.4-34.3$ \\
\hline \multicolumn{2}{|c|}{ Charlson comorbidity score (points) } \\
\hline Mean (SD) & $3.7(2.0)$ \\
\hline Median (IQR) & $3(3)$ \\
\hline 10th-90th percentile interval & $2-6$ \\
\hline \multicolumn{2}{|c|}{ Prior renal replacement modality (\%) } \\
\hline Conventional hemodialysis & 70.2 \\
\hline Intensive hemodialysis & 3.8 \\
\hline Peritoneal dialysis & 6.7 \\
\hline Kidney transplant & 2.9 \\
\hline Incident ESRD & 16.3 \\
\hline \multicolumn{2}{|l|}{ Prior dialysis duration (months) } \\
\hline Mean (SD) & $36.9(55.2)$ \\
\hline Median (IQR) & $18(35)$ \\
\hline 10th-90th percentile interval & $0-127$ \\
\hline \multicolumn{2}{|l|}{ History of kidney transplant (\%) } \\
\hline No & 63.5 \\
\hline Yes & 36.5 \\
\hline
\end{tabular}

Abbreviations: ESRD end stage renal disease, IQR interquartile range, $S D$ standard deviation

ultrafiltration rate was $<7 \mathrm{~mL} / \mathrm{hour} / \mathrm{kg}$, and over $80 \%$ of patients had ultrafiltration rate $<10 \mathrm{~mL} / \mathrm{hour} / \mathrm{kg}$.

Biochemical parameters are displayed in Table 4. Mean changes between baseline and months 3 and 6 were modest. Serum bicarbonate increased by $1 \mathrm{mmol} / \mathrm{L}$ between baseline and month 6 , whereas serum potassium decreased by $0.2 \mathrm{mmol} / \mathrm{L}$. Calcium and phosphorus were stable, while serum albumin and $\mathrm{C}$-reactive protein increased during follow-up. The percentage of patients
Table 2 Home hemodialysis prescription factors

\begin{tabular}{|c|c|}
\hline & Percentage \\
\hline \multicolumn{2}{|c|}{ Hemodialysis sessions per week (\%) } \\
\hline 4 & 1.9 \\
\hline 5 & 24.0 \\
\hline 6 & 70.2 \\
\hline 7 & 3.8 \\
\hline \multicolumn{2}{|c|}{ Hours per hemodialysis session (\%) } \\
\hline $2.0-2.4$ & 30.8 \\
\hline $2.5-2.9$ & 41.3 \\
\hline $3.0-3.4$ & 22.1 \\
\hline$\geq 3.5$ & 5.8 \\
\hline \multicolumn{2}{|c|}{ Hemodialysis hours per week (\%) } \\
\hline $10.0-11.9$ & 7.7 \\
\hline $12.0-14.9$ & 24.0 \\
\hline $15.0-17.9$ & 47.1 \\
\hline$\geq 18.0$ & 21.2 \\
\hline \multicolumn{2}{|l|}{ Dialysate preparation (\%) } \\
\hline Premixed dialysate & 39.4 \\
\hline Dialysate concentrate & 60.6 \\
\hline \multicolumn{2}{|c|}{ Dialysate liters per session (\%) } \\
\hline 15 & 2.9 \\
\hline 20 & 39.4 \\
\hline 25 & 31.7 \\
\hline 30 & 25.0 \\
\hline 40 & 1.0 \\
\hline \multicolumn{2}{|c|}{ Vascular access modality (\%) } \\
\hline Catheter & 17.3 \\
\hline Graft & 2.9 \\
\hline Fistula & 79.8 \\
\hline \multicolumn{2}{|c|}{ Cannulation technique ${ }^{\mathrm{a}}(\%)$} \\
\hline Sharp needle & 8.4 \\
\hline Buttonhole needle & 80.7 \\
\hline Plastic needle & 10.8 \\
\hline
\end{tabular}

${ }^{a}$ In patients with a fistula

with serum C-reactive protein $>10 \mathrm{mg} / \mathrm{L}$ increased from $22 \%$ at baseline to $30 \%$ at month 6 .

Medication use is displayed in Table 5. The mean number of antihypertensive agents per day fell significantly $(P<0.001)$, from 1.46 at baseline to 1.01 at month 6 . The percentage of patients using no antihypertensive agents increased from $31 \%$ at baseline to $41 \%$ at month 6 , while the percentage of patients using $>2$ antihypertensive agents per day decreased from 23 to 11\%. Phosphate binder pill count and ESA dose were stable. The percentage of patients using no heparin for anticoagulation nearly doubled between baseline and month $6(P<0.001)$. 

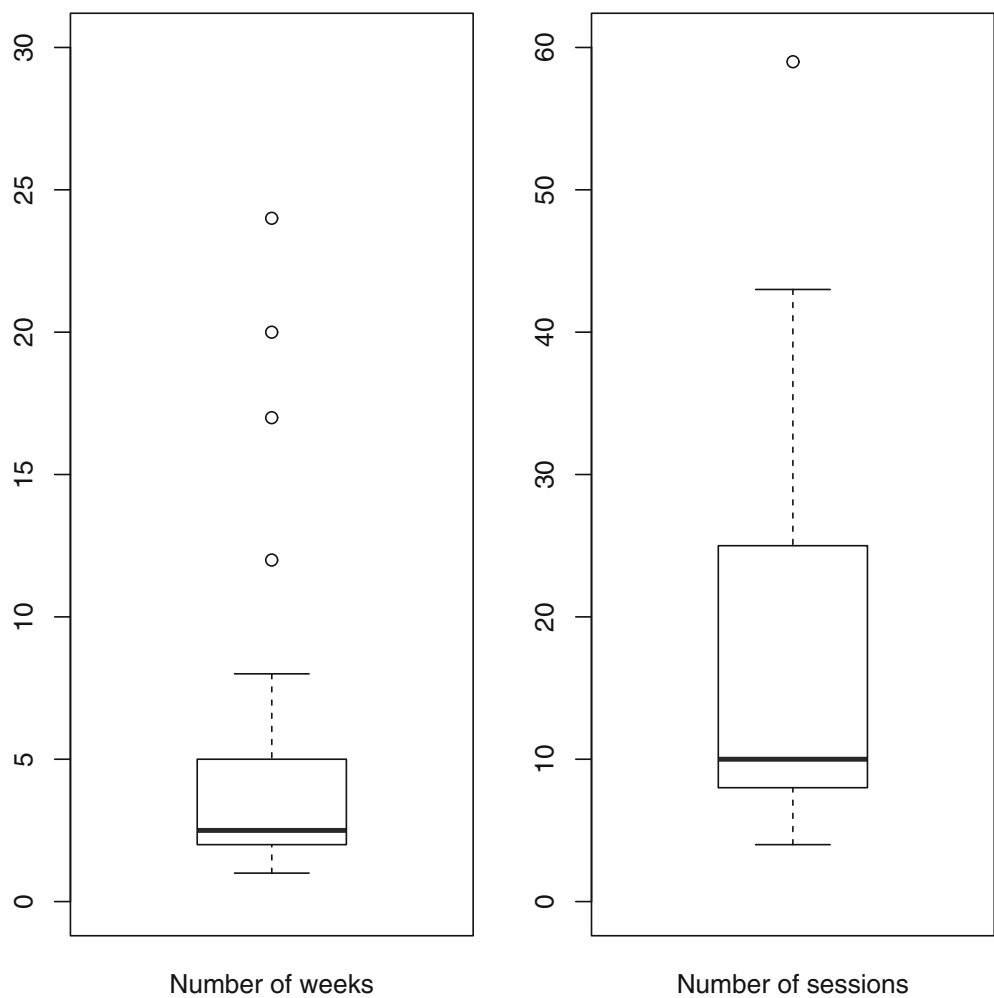

Fig. 2 Box plots of numbers of home hemodialysis training weeks and sessions. Each plot displays the median (bold line), the interquartile range (box), and outlying intervals less than or equal to 1.5 times the interquartile range (whiskers)

Mean follow-up duration was 18.8 months. During follow-up, there were 17 kidney transplants, 8 returns to in-center hemodialysis, and 6 deaths. After the first 6 months of follow-up, transplant and death rates were 15.3 and 5.4 events per 100 patient-years, respectively. At 24 months after HHD initiation, the cumulative incidence of kidney transplant, return to in-center hemodialysis, and death was $20 \%, 8 \%$, and $6 \%$, respectively. At 48 months after HHD initiation, corresponding estimates of cumulative incidence were $32 \%, 10 \%$, and $15 \%$. Thus, approximately $43 \%$ of patients remained on HHD at 48 months after HHD initiation (Fig. 3). Returns to in-center hemodialysis were due to medical complications in 2 cases and psychosocial problems in 6 cases.

\section{Discussion}

HHD continues to have limited penetration in Europe and is not currently offered as an option to all ESRD patients. In the most recent annual report of the European Renal Association-European Dialysis and Transplant Association (ERA-EDTA), the highest percentages of dialysis patients on HHD were in Finland (7.1\%), Denmark (5.8\%), the Netherlands (4.4\%), the UK (4.3\%), and Sweden (3.6\%); corresponding percentages in all other countries were less than 3\% [15]. The reasons for low use of HHD are myriad, but primary reasons include the relative simplicity of peritoneal dialysis and the shortage of patient-friendly hemodialysis equipment for application in the home setting [16]. In the KIHDNEy cohort, HHD patients used equipment that employs lactate-buffered, ultrapure dialysate, which is either supplied in premixed bags or produced from concentrate and tap water (without a reverse osmosis system). Each treatment consumes 15 to $60 \mathrm{l}$ of dialysate, which flow at a maximum rate of $200 \mathrm{~mL} /$ minute. From the patient's perspective, the device presents a relatively simple user interface, is sufficiently small to transport, and requires neither electrical nor plumbing modifications to the home; the costs of those modifications are ordinarily between $\$ 1000$ and $\$ 4000$ [17]. In this observational study, we evaluated patient and treatment factors, biochemical outcomes, and clinical outcomes in European patients on intensive HHD with low-volume dialysate. Despite its modest sample size, this study is the largest study of European patients on such treatment.

The mean age of patients in the KIHDNEy cohort was almost 50 years. That is roughly 10 years less than the mean age of prevalent ESRD patients in many European countries [15], but similar to the relative youthfulness of HHD patients in the United States $[18,19]$. The majority of patients were male, in concordance with HHD populations in North America, Australia, and New Zealand 
Table 3 Urea clearance, ultrafiltration volume, and ultrafiltration rate in home hemodialysis patients

\begin{tabular}{lll}
\hline & Month 3 & Month 6 \\
\hline Standard $K t N_{\text {urea }}$ & & \\
Patients $(n)$ & 87 & 87 \\
Mean (SD) & $2.67(0.49)$ & $2.69(0.55)$ \\
Median (IQR) & $2.63(0.46)$ & $2.63(0.57)$ \\
10th-90th percentile interval & $2.14-3.30$ & $2.09-3.49$ \\
Ultrafiltration volume ${ }^{\text {a }(L)}$ & & \\
Patients ( $n)$ & 32 & 32 \\
Mean (SD) & $1.07(0.84)$ & $1.08(0.87)$ \\
Median (IQR) & $1.00(1.02)$ & $1.00(0.92)$ \\
10th-90th percentile interval & $0.20-2.00$ & $0.20-2.00$ \\
Ultrafiltration rate (mL/hour/kg) & & \\
Patients ( $n$ ) & 32 & 32 \\
Mean (SD) & $6.54(4.85)$ & $6.82(5.61)$ \\
Median (IQR) & $6.21(6.35)$ & $6.46(5.11)$ \\
10th-90th percentile interval & $1.51-13.95$ & $0.76-11.88$ \\
\hline
\end{tabular}

Abbreviations: IQR interquartile range, $S D$ standard deviation

a Per hemodialysis session

$[18,20,21]$. Furthermore, the prevalence of diabetes as the primary etiology of ESRD was low. However, characterization of the KIHDNEy cohort as a collection of young, healthy men is inaccurate. Age ranged from 19 to 75 years and the Charlson comorbidity score ranged from 2 to 10 points. Notably, body mass index ranged from 13 (underweight) to 51 (obese). Thus, HHD appears to be a viable dialytic modality across a wide array of patients, including patients in poorer health. This observation contradicts the assumption that HHD is feasible exclusively in younger patients with limited comorbidity. In the KIHDNEy cohort, more than $70 \%$ of patients converted from in-center hemodialysis to HHD, and mean dialysis duration at HHD initiation was more than 3 years. In the United States, HHD is also commonly prescribed subsequently to in-center hemodialysis [18].

Almost all patients in the KIHDNEy cohort were prescribed either 5 or 6 treatments per week. Because treatment duration was typically between 2.0 and $3.5 \mathrm{~h}$, over $70 \%$ of patients accumulated at least 15 treatment hours per week. By comparison, large majorities of in-center hemodialysis patients in France, Italy, Spain, and the UK accumulate no more than 12 treatment hours per week [22]. The ease of delivering more treatment hours per week in the home setting is one of the primary advantages of HHD. The most commonly prescribed dialysate volume was $20 \mathrm{l}$ per session and most patients dialyzed against 20 to $30 \mathrm{l}$ per session. The majority of patients used a fistula and cannulated with a buttonhole needle. Buttonhole cannulation may be associated with increased risks of local and systemic
Table 4 Biochemical parameters in home hemodialysis patients

\begin{tabular}{|c|c|c|c|c|}
\hline & Baseline & Month 3 & Month 6 & $p^{a}$ \\
\hline \multicolumn{5}{|l|}{ Bicarbonate (mmol/L) } \\
\hline Mean (SD) & $23.1(3.5)$ & $24.1(2.8)$ & $24.1(2.9)$ & \multirow[t]{3}{*}{0.01} \\
\hline Median (IQR) & $23.3(4.2)$ & $24.0(4.0)$ & $24.0(3.5)$ & \\
\hline 10th-90th percentile interval & $18.0-27.3$ & $20.7-27.5$ & $20.0-28.0$ & \\
\hline \multicolumn{5}{|l|}{ Potassium (mmol/L) } \\
\hline Mean (SD) & $4.80(0.63)$ & $4.64(0.71)$ & $4.59(0.78)$ & \multirow[t]{3}{*}{0.01} \\
\hline Median (IQR) & $4.80(0.90)$ & $4.60(1.10)$ & $4.40(1.00)$ & \\
\hline 10th-90th percentile interval & $3.9-5.6$ & $3.8-5.5$ & $3.8-5.6$ & \\
\hline \multicolumn{5}{|l|}{ Calcium (mmol/L) } \\
\hline Mean (SD) & $2.29(0.19)$ & $2.30(0.20)$ & $2.28(0.19)$ & \multirow[t]{3}{*}{0.43} \\
\hline Median (IQR) & $2.30(0.24)$ & $2.29(0.22)$ & $2.30(0.23)$ & \\
\hline 10th-90th percentile interval & $2.03-2.52$ & $2.06-2.53$ & $2.04-2.49$ & \\
\hline \multicolumn{5}{|l|}{ Phosphorus (mmol/L) } \\
\hline Mean (SD) & $1.73(0.49)$ & $1.67(0.49)$ & $1.68(0.48)$ & \multirow[t]{3}{*}{0.38} \\
\hline Median (IQR) & $1.64(0.72)$ & $1.64(0.66)$ & $1.62(0.60)$ & \\
\hline 10th-90th percentile interval & $1.16-2.40$ & $1.10-2.33$ & $1.11-2.28$ & \\
\hline \multicolumn{5}{|l|}{ Albumin $(g / L)$} \\
\hline Mean (SD) & $36.8(5.2)$ & $37.5(4.0)$ & $37.8(4.5)$ & \multirow[t]{3}{*}{0.03} \\
\hline Median (IQR) & $37.0(5.0)$ & $37.0(5.0)$ & $38.0(6.0)$ & \\
\hline 10th-90th percentile interval & $31.0-43.0$ & $32.3-43.0$ & $38.0-50.0$ & \\
\hline \multicolumn{5}{|l|}{ Hemoglobin (g/dL) } \\
\hline Mean (SD) & $11.4(1.5)$ & $11.1(1.6)$ & $11.2(1.4)$ & \multirow[t]{3}{*}{0.25} \\
\hline Median (IQR) & $11.5(1.7)$ & $11.1(1.9)$ & $11.1(2.0)$ & \\
\hline 10th-90th percentile interval & $9.2-13.5$ & $9.2-13.0$ & $9.5-13.1$ & \\
\hline \multicolumn{5}{|l|}{ Beta-2-microglobulin (mg/L) } \\
\hline Mean (SD) & $23.6(9.7)$ & $26.8(12.5)$ & $25.4(10.8)$ & \multirow[t]{3}{*}{0.64} \\
\hline Median (IQR) & $22.0(14.7)$ & $25.3(15.1)$ & $24.0(14.2)$ & \\
\hline 10th-90th percentile interval & $10.3-36.3$ & $14.4-42.7$ & $13.7-42.0$ & \\
\hline \multicolumn{5}{|l|}{ C-reactive protein (mg/L) } \\
\hline Mean (SD) & $7.3(8.9)$ & $11.4(16.6)$ & $12.4(24.8)$ & \multirow[t]{3}{*}{0.05} \\
\hline Median (IQR) & $4.4(7.2)$ & $5.0(12.3)$ & $5.0(12.0)$ & \\
\hline 10th-90th percentile interval & $1.0-18.0$ & $0.7-31.0$ & $0.9-30.0$ & \\
\hline
\end{tabular}

Abbreviations: IQR interquartile range, $S D$ standard deviation

a From test of linear trend across displayed times

infection, although mupirocin prophylaxis may greatly reduce risk $[23,24]$. Slightly more than $17 \%$ of patients in the KIHDNEy cohort used a catheter. Catheters are widely used by HHD patients in Canada [21] and do not constitute an absolute contraindication to HHD.

HHD training, which is more complex than peritoneal dialysis training, is an obstacle to the growth of HHD. Needed nursing labor and corresponding costs may be substantial. In the Frequent Hemodialysis Network (FHN) Nocturnal Trial, patients required an average of 27.7 training sessions, which spanned between 11 and 59 days [17]. However, patients in that trial used 
Table 5 Medication use in home hemodialysis patients

\begin{tabular}{|c|c|c|c|c|}
\hline & Baseline & Month 3 & Month 6 & $p^{a}$ \\
\hline \multicolumn{5}{|c|}{ Antihypertensive medication use (agents/day) } \\
\hline Mean (SD) & $1.46(1.49)$ & $1.10(1.29)$ & $1.01(1.11)$ & \multirow[t]{3}{*}{$<0.001$} \\
\hline Median (IQR) & $1(2)$ & $1(1)$ & $1(1)$ & \\
\hline 10th-90th percentile interval & $0-4$ & $0-3$ & $0-3$ & \\
\hline \multicolumn{5}{|l|}{ Phosphate binder use (pills/day) } \\
\hline Mean (SD) & $3.25(2.91)$ & $3.13(2.66)$ & $3.21(2.84)$ & \multirow[t]{3}{*}{0.83} \\
\hline Median (IQR) & $3(4)$ & $3(3)$ & $3(5)$ & \\
\hline 10th-90th percentile interval & $0-6$ & $0-6$ & $0-6$ & \\
\hline \multicolumn{5}{|l|}{ ESA dose (EPO-equivalent IU/week) } \\
\hline Mean (SD) & $8792(6936)$ & $8211(6654)$ & $8551(7086)$ & \multirow[t]{3}{*}{0.57} \\
\hline Median (IQR) & $8000(6000)$ & $7750(6000)$ & $8000(8000)$ & \\
\hline 10th-90th percentile interval & $2000-17,000$ & $1250-16,000$ & $0-16,125$ & \\
\hline \multicolumn{5}{|l|}{ Anticoagulant use ${ }^{\mathrm{b}}(\%)$} \\
\hline No & 21.4 & NR & 40.2 & \multirow[t]{2}{*}{$<0.001$} \\
\hline Yes & 78.6 & $N R$ & 59.8 & \\
\hline
\end{tabular}

Abbreviations: EPO epoetin alfa, ESA erythropoiesis-stimulating agent, IQR interquartile range, IU international units, NR not recorded, $S D$ standard deviation

${ }^{\text {a }}$ From test of linear trend across displayed times

${ }^{\mathrm{b}}$ Heparin use during hemodialysis session

traditional hemodialysis equipment in the home setting. Patients in the KIHDNEy cohort required an average of 16.8 training sessions. This apparent reduction in training intensity may reflect the simple user interface of the equipment. On the other hand, this reduction may reflect that some patients were familiar with self-cannulation before commencing HHD training. More research about the nature of HHD training is needed. Ultimately, equipment that permits more rapid training can improve the economic feasibility of HHD. Despite the rapid pace of training in the KIHDNEy cohort, we observed good patient retention after the first 6 months of HHD. The rate of death was relatively low, whereas the rate of kidney transplant was relatively high. However, the magnitude of the transplant rate may primarily reflect the age distribution of the KIHDNEy cohort, as nearly all patients were non-elderly; whether HHD directly influences the likelihood of transplant is unknown. We also observed that most returns to in-center hemodialysis occurred in the first 12 months of follow-up and were attributable to psychosocial problems. High incidence of technique failure during the first year of HHD has been observed in the United States [19], and in the FHN Nocturnal Trial, HHD increased perceived caregiver burden [25].

Although intensive HHD with low-flow dialysate is widely used in the United States and is associated with lower risk of death and similar risk of hospitalization, relative to thrice-weekly in-center hemodialysis $[5,6]$, very little data about solute clearance and biochemistry with this therapeutic approach have been published. Kraus et al. reported that mean standard $\mathrm{Kt} / V_{\text {urea }}$ was nearly 2.3 in patients who were prescribed 6 sessions per week [26]. In the KIHDNEy cohort, mean standard $\mathrm{Kt} /$ $V_{\text {urea }}$ was nearly 2.7 at both 3 and 6 months after HHD initiation. Furthermore, roughly $90 \%$ of patients achieved standard $K t / V_{\text {urea }}$ of $\geq 2.1$, even without accounting for residual function. Adequate small solute clearance with low-volume dialysate is achievable because the dialysate is highly saturated when the blood flow rate is high and the dialysate flow rate is low. On average, ultrafiltration intensity was low. Multiple studies correlate lower ultrafiltration rate with improved survival and shorter post-dialysis recovery time [27-29]. Changes in biochemistry were generally modest. Serum concentrations of calcium, phosphorus, hemoglobin, and beta-2-microglobulin did not change significantly. The absence of a significant decline in serum phosphorus contrasts with the effect of intensive hemodialysis in the FHN Daily Trial [30]. It is possible that while dialytic clearance of phosphorus increased after HHD initiation [31], dietary intake of phosphorus also increased; to that point, serum albumin increased significantly. Mean serum potassium declined after initiation of HHD, although the 10th-90th percentile range was unchanged. The decline probably reflects the effect of shortening the usual interdialytic interval. Finally, serum C-reactive protein (CRP) increased. Serum CRP > $10 \mathrm{mg} / \mathrm{L}$ most often reflects acute or chronic inflammation [32]. Infection may have contributed to the increase, as infection - specifically, vascular access infection - has 
been reported to be a challenge with HHD [33]. We did not collect data regarding vascular access complications, so the incidence of access infection in the KIHDNEy cohort is unknown. However, serum CRP data suggest that dialysis centers should closely monitor signs of infection on HHD, including tenderness and localized redness at the buttonhole site [34].

Regarding medication use, there were no significant changes in either phosphate binder use or erythropoiesisstimulating agent dose. There was a significant decline in antihypertensive medication use between baseline and follow-up; the same change was observed in the Following Rehabilitation, Economics and Everyday-Dialysis Outcome Measurements (FREEDOM) Study of short daily HHD [35]. Intensive hemodialysis reduces pre-dialysis systolic blood pressure and the need for antihypertensive medications $[11,36]$. We did not collect longitudinal data about blood pressure, but the significant decline in medication use is compatible with a reduction in systolic blood pressure. The percentage of patients who did not require heparin administration nearly doubled after 6 months of HHD. Less need for anticoagulation may have been due to the absence of an air-blood interface in the disposable cartridge in the hemodialysis machine, lower session duration, and possibly, better volume control.
The primary limitations of this study are the small sample size and the brief follow-up interval. Many trends in the KIHDNEy cohort suggest hypotheses that require confirmation in prospective studies with larger sample size and longer follow-up. Nevertheless, this study is one of the largest analyses of biochemistry in patients on intensive HHD with low-flow dialysate. A secondary limitation of this study is the absence of controls, with respect to either hemodialysis setting, frequency, or equipment. Trends in the KIHDNEy cohort cannot be attributed directly to the home setting, intensive hemodialysis, or equipment. In addition, all patients in the KIHDNEy cohort were prescribed diurnal HHD; these data offer no insight into biochemical and clinical outcomes on nocturnal HHD with low-volume dialysate.

\section{Conclusions}

HHD is a unique modality, insofar as it offers the opportunity to individualize treatment and specifically, to increase treatment intensity beyond what is typically feasible in the center setting. For HHD to be attractive to both physicians and patients, HHD equipment must maintain provide good clinical outcomes and be sufficiently easy for patients to use. Preliminary data in the KIHDNEy cohort suggest that transportable equipment

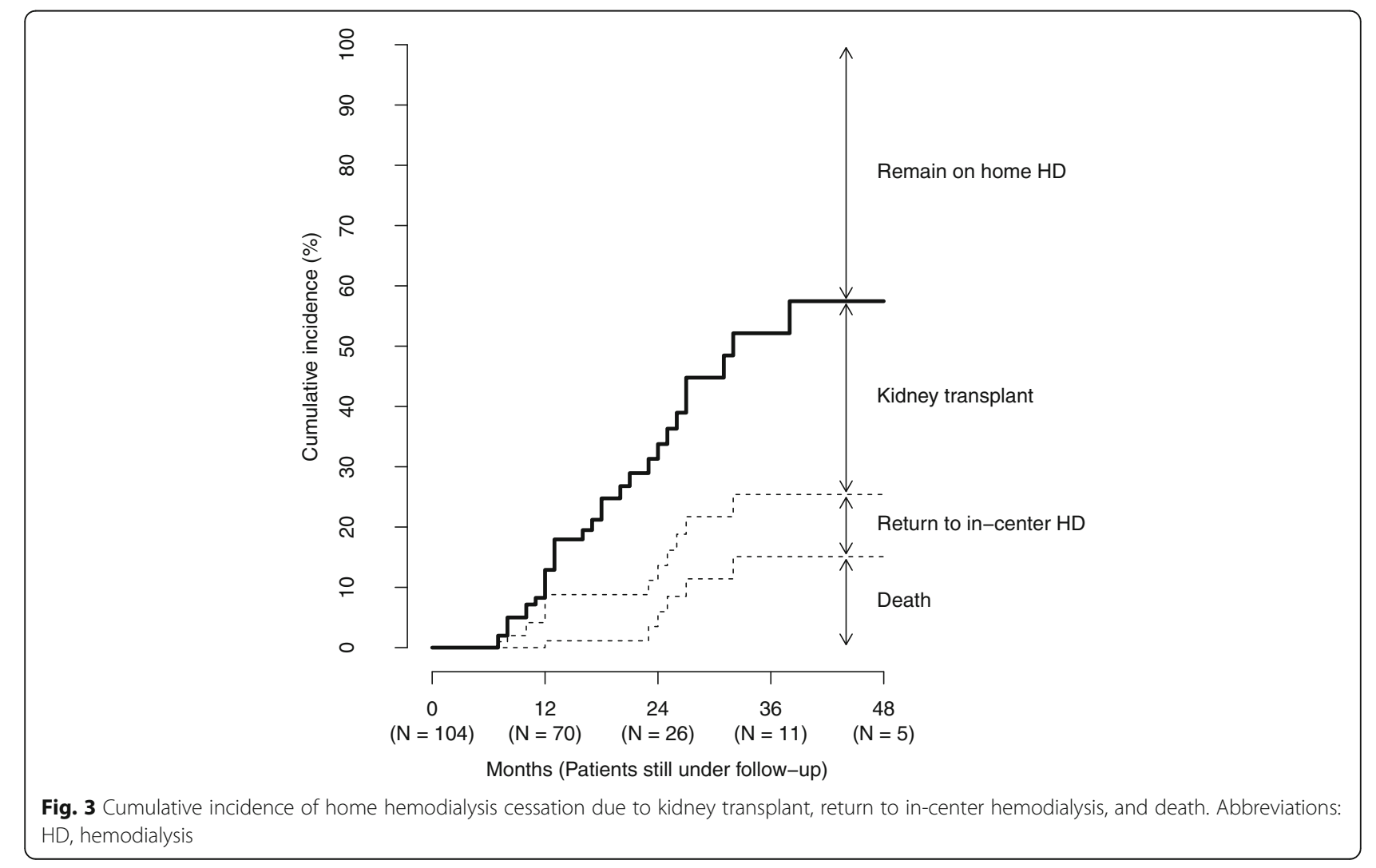


that employs low-flow dialysate achieves these objectives when patients are prescribed $>3$ sessions per week. However, infection may pose a risk in HHD patients. Ultimately, larger studies of European patients are needed to better understand clinical outcomes associated with this emerging therapeutic approach.

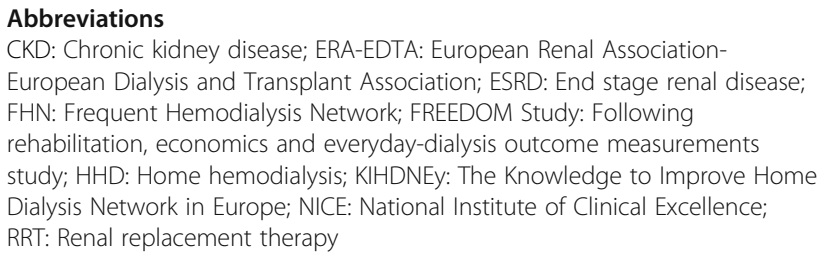

\section{Acknowledgements}

The authors thank Susan Everson, PhD, for proofreading and organizing references. Dr. Everson is a consultant to NxStage Medical.

\section{Funding}

All authors except Dr. Weinhandl collected data in the course of clinical care. Those authors voluntarily entered data in a standardized digital form; NxStage Medical provided no compensation for extraction and recording of data. Dr. Weinhandl, a clinical epidemiologist and biostatistician, coordinated statistical analysis of data.

\section{Availability of data and materials}

Anonymized datasets about cohort and follow-up parameters are available from the corresponding author upon reasonable request.

\section{Authors' contributions}

$M B, G C, R C, H F, M F, M S$, and NB conceived the study and recorded data. EW was primarily responsible for processing and analyzing data. SC, EW, and NB were primarily responsible for data interpretation and initial writing. MB, GC, $\mathrm{RC}, H F, M F$, and MS critically reviewed initial writing and suggested revisions. All authors gave final approval of the submitted manuscript and are accountable for all aspects of the work.

\section{Ethics approval and consent to participate}

We recorded, transmitted, and analyzed existing, anonymized data. Patient consent to use of retrospective data was not obtained. Per United States Code of Federal Regulations, Title 45, Part 46, this study was deemed to be exempt from review by an institutional review board.

\section{Consent for publication}

This issue is not applicable.

\section{Competing interests}

All authors except Dr. Weinhandl are members of the NxStage European Medical Board. Members receive nominal compensation for participation. Dr. Weinhandl is an employee of NxStage Medical.

\section{Publisher's Note}

Springer Nature remains neutral with regard to jurisdictional claims in published maps and institutional affiliations.

\footnotetext{
Author details

${ }^{1}$ Royal Wolverhampton Hospital, Renal Services, Wolverhampton, England. ${ }^{2}$ Hospital Universitario La Paz, Servicio de Nefrologia, Madrid, Spain. ${ }^{3}$ Niguarda Hospital, Nefrologia - Centro Trapianti Rene, Milan, Italy. ${ }^{4}$ Policlinic University, Azienda Ospedaliero-Universitaria Consorziale Policlinico, Bari, Italy. ${ }^{5}$ Hôpital Tenon, Service de Néphrologie et Dialyses, Paris, France. ${ }^{6} \mathrm{CHR}$ Clémenceau, Service Néphrologie-Hémodialyse-Transplantation, Caen, France. ${ }^{7}$ Hospital de Navarra, Servicio de Nefrologia, Pamplona, Spain. ${ }^{8} \mathrm{NxStage}$ Medical, Inc., 350 Merrimack Street, Lawrence, MA 01843, USA. ${ }^{9}$ Department of Pharmaceutical Care and Health Systems, University of Minnesota, Minneapolis, MN, USA. ${ }^{10}$ Queen Alexandra Hospital, Wessex Kidney Centre, Portsmouth, England.
}

Received: 14 May 2018 Accepted: 26 September 2018

Published online: 11 October 2018

\section{References}

1. Liyanage T, Ninomiya T, Jha V, Neal B, Patrice HM, Okpechi I, Zhao MH, LV J, Garg AX, Knight J, et al. Worldwide access to treatment for end-stage kidney disease: a systematic review. Lancet (London England). 2015; 385(9981):1975-82.

2. MacNeill SJ, Casula A, Shaw C, Castledine C. UK Renal Registry 18th Annual Report: Chapter 2 UK Renal Replacement Therapy Prevalence in 2014: National and Centre-specific analyses. Nephron. 2016;132(Suppl 1):41-68.

3. Saran R, Robinson B, Abbott KC, Agodoa LY, Ayanian J, Bragg-Gresham J, Balkrishnan R, Chen JL, Cope E, Eggers PW, et al. US renal data system 2016 annual data report: epidemiology of kidney disease in the United States. Am J Kidney Dis. 2017;69(3s1):A7-a8.

4. Pippias M, Kramer A, Noordzij M, Afentakis N, de la Alonso Torre R, Ambuhl PM, Aparicio Madre MI, Arribas Monzon F, Asberg A, Bonthuis M, et al. The European renal association - European Dialysis and transplant association registry annual report 2014: a summary. Clin Kidney J. 2017;10(2):154-69.

5. Weinhandl ED, Liu J, Gilbertson DT, Arneson TJ, Collins AJ. Survival in daily home hemodialysis and matched thrice-weekly in-center hemodialysis patients. J Am Soc Nephrol. 2012;23(5):895-904.

6. Weinhandl ED, Nieman KM, Gilbertson DT, Collins AJ. Hospitalization in daily home hemodialysis and matched thrice-weekly in-center hemodialysis patients. Am J Kidney Dis. 2015;65(1):98-108.

7. Culleton BF, Walsh M, Klarenbach SW, Mortis G, Scott-Douglas N, Quinn RR, Tonelli M, Donnelly S, Friedrich MG, Kumar A, et al. Effect of frequent nocturnal hemodialysis vs conventional hemodialysis on left ventricular mass and quality of life: a randomized controlled trial. Jama. 2007;298(11): 1291-9.

8. Chertow GM, Levin NW, Beck GJ, Depner TA, Eggers PW, Gassman JJ, Gorodetskaya I, Greene T, James S, Larive B, et al. In-center hemodialysis six times per week versus three times per week. N Engl J Med. 2010;363(24): 2287-300.

9. Rocco MV, Lockridge RS Jr, Beck GJ, Eggers PW, Gassman JJ, Greene T, Larive B, Chan CT, Chertow GM, Copland M, et al. The effects of frequent nocturnal home hemodialysis: the frequent hemodialysis network nocturnal trial. Kidney Int. 2011;80(10):1080-91.

10. McCullough PA, Chan CT, Weinhandl ED, Burkart JM, Bakris GL. Intensive hemodialysis, left ventricular hypertrophy, and cardiovascular disease. Am J Kidney Dis. 2016;68(5s1):S5-s14.

11. Bakris $G L$, Burkart JM, Weinhandl ED, McCullough PA, Kraus MA. Intensive hemodialysis, blood pressure, and antihypertensive medication use. Am J Kidney Dis. 2016;68(5s1):S15-s23.

12. Copland M, Komenda P, Weinhandl ED, McCullough PA, Morfin JA. Intensive hemodialysis, mineral and bone disorder, and phosphate binder use. Am J Kidney Dis. 2016;68(5s1):S24-s32.

13. Suri RS, Larive B, Sherer S, Eggers P, Gassman J, James SH, Lindsay RM, Lockridge RS, Ornt DB, Rocco MV, et al. Risk of vascular access complications with frequent hemodialysis. J Am Soc Nephrol. 2013;24(3):498-505.

14. National Institute for Health and Care Excellence. Renal replacement therapy services for adults. Quality standard [QS72]. 2014; https://www.nice. org.uk/guidance/qs72/chapter/about-this-quality-standard.

15. ERA-EDTA Registry. ERA-EDTA Registry Annual Report 2015. Amsterdam, the Netherlands: Academic Medical Center, Department of Medical Informatics; 2017.

16. Trinh $\mathrm{E}$, Chan $\mathrm{CT}$. The rise, fall, and resurgence of home hemodialysis. Semin Dial. 2017;30(2):174-80

17. Pipkin M, Eggers PW, Larive B, Rocco MV, Stokes JB, Suri RS, Lockridge RS Jr. Recruitment and training for home hemodialysis: experience and lessons from the nocturnal dialysis trial. Clin J Am Soc Nephrol. 2010;5(9): 1614-20.

18. Weinhandl ED, Gilbertson DT, Collins AJ. Mortality, hospitalization, and technique failure in daily home hemodialysis and matched peritoneal Dialysis patients: a matched cohort study. Am J Kidney Dis. 2016;67(1): 98-110.

19. Seshasai RK, Mitra N, Chaknos CM, Li J, Wirtalla C, Negoianu D, Glickman JD, Dember LM. Factors associated with discontinuation of home hemodialysis. Am J Kidney Dis. 2016;67(4):629-37. 
20. Marshall MR, Hawley CM, Kerr PG, Polkinghorne KR, Marshall RJ, Agar JW, McDonald SP. Home hemodialysis and mortality risk in Australian and New Zealand populations. Am J Kidney Dis. 2011;58(5):782-93.

21. Tennankore KK, Na Y, Wald R, Chan CT, Perl J: Short daily-, nocturnal- and conventional-home hemodialysis have similar patient and treatment survival. Kidney Int. 2018;93(1):188-94.

22. Tentori F, Zhang J, Li Y, Karaboyas A, Kerr P, Saran R, Bommer J, Port F, Akiba T, Pisoni $\mathrm{R}$, et al. Longer dialysis session length is associated with better intermediate outcomes and survival among patients on in-center three times per week hemodialysis: results from the Dialysis outcomes and practice patterns study (DOPPS). Nephrol Dial Transplant. 2012;27(11):4180-8.

23. Wong B, Muneer M, Wiebe N, Storie D, Shurraw S, Pannu N, Klarenbach S, Grudzinski A, Nesrallah G, Pauly RP. Buttonhole versus rope-ladder cannulation of arteriovenous fistulas for hemodialysis: a systematic review. Am J Kidney Dis. 2014:64(6):918-36.

24. Nesrallah GE, Cuerden M, Wong JH, Pierratos A. Staphylococcus aureus bacteremia and buttonhole cannulation: long-term safety and efficacy of mupirocin prophylaxis. Clin J Am Soc Nephrol. 2010;5(6):1047-53.

25. Suri RS, Larive B, Hall Y, Kimmel PL, Kliger AS, Levin N, Tamura MK, Chertow GM. Effects of frequent hemodialysis on perceived caregiver burden in the frequent hemodialysis network trials. Clin J Am Soc Nephrol. 2014;9(5):936-42.

26. Kraus M, Burkart J, Hegeman R, Solomon R, Coplon N, Moran J. A comparison of center-based vs. home-based daily hemodialysis for patients with end-stage renal disease. Hemodial Int. 2007;11(4):468-77.

27. Assimon MM, Wenger JB, Wang L, Flythe JE. Ultrafiltration rate and mortality in maintenance hemodialysis patients. Am J Kidney Dis. 2016;68(6):911-22.

28. Chazot C, Vo-Van C, Lorriaux C, Deleaval P, Mayor B, Hurot JM, Jean G. Even a moderate fluid removal rate during individualised Haemodialysis session times is associated with decreased patient survival. Blood Purif. 2017;44(2): 89-97.

29. Hussein WF, Arramreddy R, Sun SJ, Reiterman M, Schiller B. Higher ultrafiltration rate is associated with longer Dialysis recovery time in patients undergoing conventional hemodialysis. Am J Nephrol. 2017;46(1):3-10.

30. Daugirdas JT, Chertow GM, Larive B, Pierratos A, Greene T, Ayus JC, Kendrick CA, James SH, Miller BW, Schulman G, et al. Effects of frequent hemodialysis on measures of CKD mineral and bone disorder. J Am Soc Nephrol. 2012; 23(4):727-38.

31. Brunati CCM, Gervasi F, Casati C, Querques ML, Montoli A, Colussi G. Phosphate and calcium control in short frequent hemodialysis with the NxStage system one cycler: mass balance studies and comparison with standard thrice-weekly bicarbonate Dialysis. Blood Purif. 2018;45(4):334-42.

32. Beerenhout CH, Kooman JP, van der Sande FM, Hackeng C, Leunissen KM. C-reactive protein levels in dialysis patients are highly variable and strongly related to co-morbidity. Nephrol Dial Transplant. 2003;18(1):221.

33. Poon CK, Chan CT. Home hemodialysis associated infection-the "Achilles' heel" of intensive hemodialysis. Hemodial Int. 2017;21(2):155-60.

34. Christensen LD, Skadborg MB, Mortensen AH, Mortensen C, Moller JK, Lemming L, Hogsberg I, Petersen SE, Buus NH. Bacteriology of the buttonhole cannulation tract in hemodialysis patients: a prospective cohort study. Am J Kidney Dis. 2018;72(2):234-42.

35. Jaber BL, Collins AJ, Finkelstein FO, Glickman JD, Hull AR, Kraus M, McCarthy J, Miller B, Spry L. Daily Hemodialysis (DHD) Reduces the Need for AntiHypertensive Medications. In: Renal Week 2009: 2009: J Am Soc Nephrol; 2009. p. 675A.

36. Kotanko P, Garg AX, Depner T, Pierratos A, Chan CT, Levin NW, Greene T, Larive B, Beck GJ, Gassman J, et al. Effects of frequent hemodialysis on blood pressure: results from the randomized frequent hemodialysis network trials. Hemodial Int. 2015;19(3):386-401.

Ready to submit your research? Choose BMC and benefit from:
- fast, convenient online submission
- thorough peer review by experienced researchers in your field
- rapid publication on acceptance
- support for research data, including large and complex data types
- gold Open Access which fosters wider collaboration and increased citations
- maximum visibility for your research: over 100M website views per year
At BMC, research is always in progress.
Learn more biomedcentral.com/submissions

